\title{
Prevalence of symptoms of ocular surface disease in patients of ophthalmic practices
}

\author{
Manuel Garza-León1, Everardo Hernández-Quintela², Héctor G. Cámara-Castillo³, Paola de la Parra-Collin', \\ Paola Covarrubias-Espinosa ${ }^{5}$, Valeria Sánchez-Huerta², Alejandro del Castillo-Ruiz ${ }^{6}$, \\ Fernando Rodríguez-Sixtos ${ }^{7}$, Jorge Pacheco-Patrón ${ }^{8}$, Juan Carlos Ochoa-Tabares ${ }^{9}$, Karina Soto-Ortiz ${ }^{10}$ \\ and Karen Hernández-Olguin ${ }^{11}$ on behalf of the Mexican Group of Research in VIsual Sciences \\ ${ }^{1}$ Department of Clinical Sciences, Division de of Health Sciences, Universidad de Monterrey, Monterrey, N.L.; ${ }^{2}$ Department of Cornea and Refractive \\ Surgery, Hospital Dr. Luis Sánchez Bulnes, Asociación para Evitar la Ceguera en México, I.A.P., Ciudad de México; ${ }^{3}$ Clínica de Mérida, Mérida, \\ Yuc.; ${ }^{4}$ Cornea and Ocular Surface Clinic, Ophthalmology Department, Instituto Nacional de Rehabilitación, Ciudad de México; ${ }^{5} \mathrm{Hospital}$ Aranda de \\ la Parra, León, Gto.; ${ }^{6}$ Clínica Oftalmológica del Castillo S.C, Puebla, Pue.; ${ }^{7}$ Ocuclinic, Irapuato, Gto.; ${ }^{8}$ Hospital Ángeles, Chihuahua, Chih., and \\ Hospital San José, Querétaro, Qro.; ${ }^{9}$ Servicios Optométricos y Ópticos SA de CV, Clínica Santa Lucía, Guadalajara, Jal.; ${ }^{10}$ Oftalmología Médica y \\ Quirúrgica, Aguascalientes, Ags.; ${ }^{11}$ Instituto Mexicano del Seguro Social, Unidad Médica de Alta Especialidad No. 76, Hospital Mexicano-Americano, \\ Nuevo Laredo, Tamps. Mexico
}

\begin{abstract}
Objective: To determine the prevalence of symptoms of ocular surface disease (OSDI) surface disease and its relationship with associated risk factors in patients of ophthalmic practices using OSDI questionnaire. Method: A cross-sectional survey was conducted Between September and December 2014 to assess the prevalence and risk factors for OSDI. Results: The OSDI average value was $40.46 \pm 23.62$ points, with $86.4 \%$ of patients (1967) having a OSDI score higher than 12 points. Women had OSDI symptoms more frequently than men (odds ratio: 1.17; 95\% confidence interval: 1.08-1.28) and higher OSDI score (42.12 \pm 24.03 vs. $38.01 \pm 22.81$ points). Patients without disease were younger than the patients with severe disease ( $45.30 \pm 18.32$ vs. $50.62 \pm 18.86$ ). Conclusions: Ophthalmological patients have a prevalence of $80.4 \%$ of OSDI. Female and older age was associated with ocular surface disease.
\end{abstract}

KEY WORDS: Ocular surface disease. Ocular surface disease questionnaire. Dry eye. Risk factors. Ophthalmic patients.

\section{Introduction}

Dry eye is one of the most common conditions and a frequent cause for ophthalmologic consultation'. It is a multifactorial disease of the ocular surface that affects the lacrimal film causing its instability, which results in symptoms of ocular discomfort, visual disturbances and potential harm to external ocular structures ${ }^{2}$.

The prevalence of this condition has been widely studied with quite variable results, from $5 \%$ to more than $70 \%$ in people older than 50 years ${ }^{1,3-13}$; the results vary according to the definition used, the diagnostic methods and the studied population 1 .

The Ocular Surface Disease Index (OSDI) questionnaire is a widely used method in dry eye and ocular surface disease epidemiological studies, since it evaluates with 12 questions not only the symptoms associated with this condition, but also the impact on the surveyed subjects quality of life. The results of the OSDI survey can have values between 0 and 100 points and, according to the published guidelines on the OSDI results, patients can be divided in those with a normal ocular surface (0 to 12 points), mild ocular surface disease (13 to 22 points), moderate disease

\author{
Correspondence: \\ Manuel Garza-León \\ Avda. Hidalgo, 2425 Poniente \\ Col. Obispado \\ C.P. 64060 , Monterrey, N.L., México \\ E-mail: manuel.garza@udem.edu
}

Date of reception: 23-09-2016

Date of acceptance: 06-12-2016

DOI://dx.doi.org/10.24875/GMM.M18000078
Gac Med Mex. 2017;153:696-700

Contents available at PubMed www.gacetamedicademexico.com 
Table 1. Demographic data

\begin{tabular}{|c|c|c|c|c|c|}
\hline & $\begin{array}{c}\text { Patients } \\
n=2,270(100 \%)\end{array}$ & $\begin{array}{l}\text { Without disease } \\
n=303(13.3 \%)\end{array}$ & $\begin{array}{c}\text { Mild disease } \\
n=308(13.6 \%)\end{array}$ & $\begin{array}{c}\text { Moderate disease } \\
n=305(13.4 \%)\end{array}$ & $\begin{array}{c}\text { Severe disease } \\
n=1,354(59.6 \%)\end{array}$ \\
\hline Age \pm SD $(95 \% \mathrm{Cl})$ & $50 \pm 17.68$ & $\begin{array}{l}45.30 \pm 18.32 \\
(43.14-47.45)\end{array}$ & $\begin{array}{l}45.15 \pm 19.08 \\
(42.79-47.49)\end{array}$ & $\begin{array}{l}48.15 \pm 18.78 \\
(46.17-50.13)\end{array}$ & $\begin{array}{l}50.62 \pm 18.86 \\
(49.59-51.65)\end{array}$ \\
\hline Males, n (\%) & $922(40.6)$ & $146(15.8)$ & 125 (13.6) & $135(14.6)$ & $516(56)$ \\
\hline Females, n (\%) & $1348(59.4)$ & 157 (11.6) & $183(13.6)$ & $170(12.6)$ & 838 (62.2) \\
\hline
\end{tabular}

95\% Cl: $95 \%$ confidence interval; SD: standard deviation.

(23 to 32 points) and severe disease (33 to 100 points) ${ }^{14}$. For the performance of our study, we used the OSDI questionnaire in a Spanish-validated version ${ }^{15}$.

To our knowledge, in Mexico there is no published information on the prevalence of ocular surface disease symptoms in patients attending ophthalmology outpatient consultation and, with this being a public health problem ${ }^{16}$, having information on the subject is indispensable in our country.

The purpose is to know the prevalence of ocular surface disease symptoms in patients attending ophthalmology outpatient clinics for the first time in our country, as well as to know the relationship between the symptoms and the age and gender of patients attending institutional and private outpatient clinics.

\section{Method}

A survey was carried out between September and December 2014 in public and private ophthalmology high specialty centers by doctors who are members of the Mexican Group of Research in Visual Sciences from 19 of the 32 States of the Mexican Republic. The Spanish-translated and validated OSDI questionnaire was used ${ }^{15}$ in patients who attended an ophthalmology clinic for the first time, to be autonomously answered prior to entering the office. In case the patient had any doubt, it was directly solved by the specialist physician.

Patients older than 18 years, of either gender, who voluntarily agreed to participate in the study were consecutively included. Patients with any signs and/ or symptoms of ocular surface active infection, eyelid structural or functional alterations, including facial palsy sequels, or any mental disturbance that would compromise the questionnaire comprehension, were excluded.

The capture of data was carried out via Internet by means of a site that was specifically created for that purpose. In addition to the OSDI questionnaire, the following data were collected: patient ID, date the questionnaire was filled, date of birth, gender, place of referral (institutional or private practice), name of the physician and additional comments.

Statistical analysis was carried out with the statistical program R ( $\mathrm{R}$ Core Central, 2015) to analyze the results, and with the Stan software (Stan development team, 2016. RStan: R-to-Stan interface, Version 2.9.0. http://mc-stan.org) for the beta Bayesian regression model.

According to previous studies in our population (data not published), our hypothesis is that the prevalence of ocular surface disease symptoms is higher than $50 \%$.

\section{Results}

Out of 2270 participants, 1348 (59.8\%) were females and $922(40.2 \%)$ were males, with an average age of $50 \pm 17.68$ years (range: 18-97). Females had an average age of $50.98 \pm 17.82$ years, and males, $48.56 \pm 17.37$ years; the age difference was not statistically significant $(p=0.154)$. Demographic characteristics are presented in table 1. Approximately $75 \%$ of patients answered all questions ${ }^{12}, 9 \%$ answered 11 and $5 \%$ answered 10; minimal answered questions were 5 in $1.5 \%$ of questionnaires.

Average value of the OSDI questionnaire result was $40.46 \pm 23.62$ units. Ocular surface disease symptoms were present in 1967 participants (86.4\%).

Patients without symptoms were younger than the rest (Table 1), with the difference being significant between patients without or with mild symptoms and those with severe symptoms. With regard to gender, females had higher OSDI questionnaire values than males $(p=0.001)$, with $41.12 \pm 24.03$ vs. $38.01 \pm$ 22.81, respectively, and, in addition, showed more severe symptoms than males (Table 1 ).

Table 2 shows risk factors effect estimates (through the Beta regression model). Females are prone to score higher OSDI values than males (odds ratio [OR]: 
Table 2. Estimated effects with risk factors relative risk

\begin{tabular}{lcc}
\hline Factor & $\mathbf{R R}$ & $\mathbf{9 5 \%} \mathbf{~ C l}$ \\
\hline Female & 1.17 & $1.08-1.28$ \\
Age & 1.32 & $1.21-1.43$ \\
Physician's specialty (vs. anterior segment) & & \\
Ocular inflammatory diseases & 0.44 & $0.34-0.57$ \\
Retina & 0.82 & $0.67-0.98$ \\
Cornea & 1.01 & $0.90-1.14$ \\
Glaucoma & 1.05 & $0.90-1.23$ \\
\hline $95 \%$ Cl: 95\% confidence interval. RR: reative risk. & &
\end{tabular}

95\% Cl: $95 \%$ confidence interval: $\mathrm{RR}$ : relative risk.

1.17; 95\% confidence interval [CI]: 1.08-1.28). Older patients are prone to score higher OSDI values (RR: 1.32; $95 \% \mathrm{Cl}: 1.21-1.43)$. The patients of specialists in ocular inflammatory diseases and retina tended to score lower OSDI values than those who were referred by anterior segment specialist physicians (RR: 0.44; 95\% Cl: $0.34-0.57$ and RR: 0.82 ; $95 \%$ Cl: $0.67-$ 0.98 , respectively).

The prevalence of ocular surface disease symptoms by age-decades is presented in table 3 . The highest OSDI questionnaire result was in patients aged from 91 to 100 years, followed by those with 81 to 90 years and those with 71 to 80 years. Although severe symptoms were predominant in all life decades, the highest frequency of severe disease was found from the sixth decade of life on, with exception of the 91 to 100-year decade, a group where the number of patients was very small, which is why the frequency of severe disease was not so high even when the OSDI questionnaire result was the highest among all age groups.

Patients were referred by physicians with different high specialty training, almost half (1073; 47.3\%), by cornea specialist physicians, followed by $493(21.7 \%)$, by anterior segment specialists, $326(14.4 \%)$, by glaucoma specialists, $290(12.8 \%)$, by retina specialists and $88(3.9 \%)$, by ocular inflammatory diseases specialists. The OSDI values by specialty are shown in table 4.

The assessed patients came both from public institutions and private practices $(81.4 \%$ of patients came from private practices). When assessing whether the patient referring source had an effect on the prevalence of ocular surface disease by means of the chisquare test, no association was found between the patient referring source and the frequency of ocular surface disease $(p=0.493)$.

\section{Discussion}

The prevalence of dry eye in the general population has great variation, which ranges from $7.8 \%$ to $57 . \%^{17-22}$ depending on the dry eye definition and the diagnostic tests performed; however, when only symptoms are taken into account, the prevalence of dry eye symptoms can be as high as $93.2 \%$, as reported by Bukhari et al. ${ }^{3}$, who studied 251 companions of patients attending ophthalmology appointments in Jeddah, Saudi Arabia. In our study, the prevalence of ocular surface disease symptoms was calculated in ophthalmologic patients; there are few studies assessing patients attending ophthalmology ${ }^{23,24}$ or optometry appointments ${ }^{25,26}$. In our study, a prevalence of symptoms of $86.4 \%$ was found, which is much higher than in other similar studies, such as the one conducted by Hikichi et al. ${ }^{23}$, who report it in $17 \%$ of adults attending ophthalmology appointments at 8 centers of Japan; however, all patients with dry eye symptoms (89 out of 2127) were excluded in their study, the questionnaire used was different and, in addition, the dry eye diagnosis was made with clinical tests and, according to reports by different authors, there is no important correlation between dry eye symptoms and signs ${ }^{27-30}$. Similar results were found by Sahai and Malik ${ }^{24}$ when assessing 500 patients attending ophthalmology appointments in Jaipur, India, using the same questionnaire as Hikichi et al ${ }^{23}$ together with clinical tests such as in vivo staining with lissamine green and fluorescein, Schirmer's test and tear film break up time, with a prevalence of $18.4 \%$ been reported; however, $55.6 \%$ referred blurry vision, which is one of the symptoms assessed in the OSDI questionnaire, which confirms the difficulty to compare these studies with the one conducted by us. Albietz ${ }^{24}$ assessed 1584 patients attending an optometry appointment for the first time in Queensland, Australia, and, using the McMonnies questionnaire, in addition to in vivo staining with fluorescein and rose Bengal and tear film break up time measurement, he found a dry eye prevalence of $10.8 \%$, which is a value lower than that reported by Doughty et al. ${ }^{26}$, who assessed the prevalence of dry eye using a 13-item questionnaire (The Canada Dry Eye Epidemiology Study [CANDEES]) in 9 Canadian provinces, and $28.7 \%$ of participants answered positively to the question of whether they had dry eye symptoms.

OSDI questionnaire scores were higher in females than in males, with a statistically significant difference (38.01 \pm 22.81 vs. $42.12 \pm 24.03$, respectively), owing 
Table 3. OSDI questionnaire results by age in decades

\begin{tabular}{|c|c|c|c|c|c|c|}
\hline Age range, years & $\mathrm{n}$ & OSDI value & Without disease $\mathrm{n}(\%)$ & Mild disease $\mathrm{n}(\%)$ & Moderate disease $\mathrm{n}(\%)$ & Severe disease $n(\%)$ \\
\hline 18 to 30 & 370 & $35.93 \pm 2.69$ & $61(16.5)$ & $64(17.3)$ & $42(11.4)$ & $203(54.9)$ \\
\hline 31 to 40 & 380 & $35.74 \pm 1.26$ & $65(17.1)$ & $67(17.6)$ & $57(15)$ & $191(50.3)$ \\
\hline 41 to 50 & 399 & $40.10 \pm 1.23$ & $54(13.5)$ & $55(13.8)$ & 49 (12.3) & $241(60.4)$ \\
\hline 51 to 60 & 449 & $44.29 \pm 1.15$ & $48(10.7)$ & $51(11.4)$ & $62(13.8)$ & $288(64.1)$ \\
\hline 61 to 70 & 336 & $41.67 \pm 1.33$ & $44(13.1)$ & $37(11 \%)$ & $47(14)$ & $208(61.9)$ \\
\hline 71 to 80 & 243 & $44.40 \pm 1.55$ & $25(10.3)$ & $25(10.3$ & $38(15.6)$ & $155(63.8)$ \\
\hline 81 to 90 & 91 & $48.40 \pm 2.50$ & $6(6.6)$ & $8(8.8)$ & $10(11)$ & $67(73.6)$ \\
\hline 91 to 100 & 2 & $54.36 \pm 16.5$ & $0(0)$ & $1(50)$ & $0(0)$ & $1(50)$ \\
\hline
\end{tabular}

Table 4. OSDI score value by referring physician specialty

\begin{tabular}{lccc}
\hline Specialty & $\mathbf{n}$ & Average $\pm \mathbf{S D}$ & $\mathbf{9 5 \%} \mathbf{C l}$ \\
\hline Cornea & 1,073 & $41.79 \pm 23.33$ & $40.39-43.19$ \\
Anterior segment & 493 & $41.31 \pm 23.45$ & $39.23-43.38$ \\
Glaucoma & 326 & $42.06 \pm 24.64$ & $39.38-44.75$ \\
Retina & 290 & $39.30 \pm 22.82$ & $36.66-41.94$ \\
Inflammatory ocular diseases & 88 & $25.45 \pm 20.25$ & $21.16-29.74$ \\
\hline
\end{tabular}

95\% Cl: 95\% confidence interval; SD: standard deviation.

to the fact that both the prevalence of ocular surface disease symptoms was higher in females (88 vs. $84.9 \%)$ and females had severe symptoms more often than males (61.5 vs. $55.3 \%$ ), which is similar to findings in most studies on dry eye, where females are observed to be affected more frequently than males ${ }^{1,4,28,31-33}$. In our study, in addition to the influence of gender-related changes, the fact that females were older than males might also have an influence and, both in our study and others ${ }^{4,25,26,31,34}$, age has a directly proportional relationship with ocular surface disease.

Patients who were referred by physicians highly specialized in retina and ocular inflammatory diseases had the lowest OSDI values; this might be due to the fact that, although some authors have found a higher prevalence of dry eye and Meibomian gland dysfunction in diabetic patients ${ }^{35-37}$, who are the most common population with retinal disease in Mexico, Fuerst et $a l .^{37}$ found that the longer the time of evolution with diabetes, the lesser the presence of symptoms, in addition to the fact that the number of patients was the second lowest, only above the patients referred by physicians specialized in ocular inflammatory diseases. As regards patients of ocular inflammatory diseases specialist physicians, although many of the conditions associated with these have an elevated prevalence of dry eye ${ }^{38-41}$, the use of steroids produces an important decrease in ocular surface disease-associated symptoms ${ }^{42-46}$.

In conclusion, our study found a very high prevalence of ocular surface disease in patients attending ophthalmology appointments in Mexico, with the female gender and increased age being the most important risk factors.

Members of the Mexican Group of Research in Visual Sciences who participated in this study: Adai Pérez Montecinos, Adolfo Peña Aceves, Alejandro del Castillo Ruiz, Alejandro Franco, Arturo Jaime Gallegos Valencia, Arturo Luis Villarreal Muraira, Carlos Carral, Cynthia Espinosa, Diana Báez, Everardo Hernández Quintela, Fabiola Barrera Pelayo, Felipe Hernández, Fernando Aguilera, Fernando Rodríguez Sixtos, Francisco Segura, Gerardo García, Gonzalo Padilla, Héctor Cámara, Jorge Pacheco Patrón, Jorge Rivera Sempertegui, Juan C. Ochoa Tabares, Karen Hernández, KarinaSoto Ortiz, Karla Chávez, Manuel Garza León, Nicolás León Pérez, Óscar del Razo, Paola Covarrubias, Paola de la Parra Colín, Ricardo Leal Rodríguez, Roberto González, Roberto Leal, Silvia Elena Vílchez Riestra, Susana Martínez Jardón and Valeria Sánchez Huerta.

\section{References}

1. The epidemiology of dry eye disease: report of the Epidemiology Subcommittee of the International Dry Eye WorkShop (2007). Ocul Surf. 2007;5:93-107.

2. The definition and classification of dry eye disease: report of the Definition and Classification Subcommittee of the International Dry Eye WorkShop (2007). Ocul Surf. 2007;5:75-92.

3. Bukhari A, Ajlan R, Alsaggaf $H$. Prevalence of dry eye in the normal population in Jeddah, Saudi Arabia. Orbit (Amsterdam, Netherlands). 2009;28:392-7.

4. Ahn JM, Lee SH, Rim TH, et al. Prevalence of and risk factors associated with dry eye: the Korea National Health and Nutrition Examination Survey 2010-2011. Am J Ophthalmol. 2014;158:1205-14.e7.

5. Gupta RC, Ranjan R, Kushwaha RN, et al. A questionnaire-based survey of dry eye disease among leather tannery workers in Kanpur, India: a case-control study. Cutan Ocul Toxicol. 2014;33:265-9. 
6. Li J, Zheng K, Deng Z, et al. Prevalence and risk factors of dry eye disease among a hospital-based population in southeast China. Eye Contact Lens. 2015;41:44-50.

7. Malet F, Le Goff M, Colin J, et al. Dry eye disease in French elderly subjects: the Alienor Study. Acta Ophthalmol. 2014:92:e429-36.

8. Paulsen AJ, Cruickshanks KJ, Fischer ME, et al. Dry eye in the beaver dam offspring study: prevalence, risk factors, and health-related quality of life. Am J Ophthalmol. 2014;157:799-806.

9. Tan LL, Morgan P, Cai ZQ, et al. Prevalence of and risk factors for symptomatic dry eye disease in Singapore. Clin Exp Optom. 2015; 98:45-53.

10. Uchino M, Uchino $\mathrm{Y}$, Dogru M, et al. Dry eye disease and work productivity loss in visual display users: the Osaka study. Am J Ophthalmol. 2014;157:294-300.

11. Uchino M, Yokoi N, Uchino $\mathrm{Y}$, et al. Prevalence of dry eye disease and its risk factors in visual display terminal users: the Osaka study. Am J Ophthalmol. 2013;156:759-66.

12. Vehof J, Kozareva D, Hysi PG, et al. Prevalence and risk factors of dry eye disease in a British female cohort. Br J Ophthalmol. 2014:98:1712-7.

13. Uchino M, Dogru M, Yagi $Y$, et al. The features of dry eye disease in a Japanese elderly population. Optom Vis Sci. 2006;83:797-802.

14. Miller KL, Walt JG, Mink DR, et al. Minimal clinically important difference for the ocular surface disease index. Arch Ophthalmol. 2010;128:94-101.

15. Beltrán F, Ramos Betancourt N, Martínez J, et al. Transcultural validation of Ocular Surface Disease Index (OSDI) questionnaire for Mexican population. Invest Ophthalmol Vis Sci. 2013;54:6050.

16. Uchino M, Schaumberg DA. Dry eye disease: impact on quality of life and vision. Current Ophthalmology Reports. 2013;1:51-7.

17. Chia EM, Mitchell $P$, Rochtchina E, et al. Prevalence and associations of dry eye syndrome in an older population: the Blue Mountains Eye Study. Clin Exp Ophthalmol. 2003;31:229-32

18. Farrell J, Grierson DJ, Patel S, et al. A classification for dry eyes following comparison of tear thinning time with Schirmer tear test. Acta Ophthalmol (Copenh). 1992;70:357-60.

19. McCarty CA, Bansal AK, Livingston PM, et al. The epidemiology of dry eye in Melbourne, Australia. Ophthalmology. 1998;105:1114-9.

20. Toda I, Fujishima H, Tsubota K. Ocular fatigue is the major symptom of dry eye. Acta Ophthalmol (Copenh). 1993;71:347-52.

21. Tong L, Saw SM, Lamoureux EL, et al. A questionnaire-based assessment of symptoms associated with tear film dysfunction and lid margin disease in an Asian population. Ophthalmic Epidemiol. 2009;16:31-7.

22. Versura $P$, Cellini M, Torreggiani A, et al. Dryness symptoms, diagnostic protocol and therapeutic management: a report on 1,200 patients. Ophthalmic Res. 2001;33:221-7.

23. Hikichi T, Yoshida A, Fukui Y, et al. Prevalence of dry eye in Japanese eye centers. Graefes Arch Clin Exp Ophthalmol. 1995;233:555-8.

24. Sahai A, Malik P. Dry eye: prevalence and attributable risk factors in a hospital-based population. Indian J Ophthalmol. 2005;53:87-91.

25. Albietz JM. Prevalence of dry eye subtypes in clinical optometry practice. Optom Vis Sci. 2000;77:357-63.

26. Doughty MJ, Fonn D, Richter D, et al. A patient questionnaire approach to estimating the prevalence of dry eye symptoms in patients presenting to optometric practices across Canada. Optom Vis Sci. 1997; 74:624-31.
27. Begley CG, Chalmers RL, Abetz L, et al. The relationship between habitual patient-reported symptoms and clinical signs among patients with dry eye of varying severity. Invest Ophthalm Vis Sci. 2003;44:4753-61.

28. Lin PY, Cheng CY, Hsu WM, et al. Association between symptoms and signs of dry eye among an elderly Chinese population in Taiwan: the Shihpai Eye Study. Invest Ophthalm Vis Sci. 2005;46:1593-8.

29. Nichols KK, Nichols JJ, Mitchell GL. The lack of association between signs and symptoms in patients with dry eye disease. Cornea. 2004;23:762-70.

30. Schein OD, Tielsch JM, Munoz B, et al. Relation between signs and symptoms of dry eye in the elderly. A population-based perspective. Ophthalmology. 1997;104:1395-401.

31. Galor A, Feuer W, Lee DJ, et al. Prevalence and risk factors of dry eye syndrome in a United States veterans affairs population. Am J Ophthalmol. 2011;152:377-84.e2.

32. Schaumberg DA, Buring JE, Sullivan DA, et al. Hormone replacement therapy and dry eye syndrome. JAMA. 2001;286:2114-9.

33. Schaumberg DA, Sullivan DA, Buring JE, et al. Prevalence of dry eye syndrome among US women. Am J Ophthalmol. 2003;136:318-26.

34. Guo B, Lu P, Chen X, et al. Prevalence of dry eye disease in Mongolians at high altitude in China: the Henan eye study. Ophthalm Epidemiol. 2010;17:234-41.

35. Najafi L, Malek M, Valojerdi AE, et al. Dry eye and its correlation to diabetes microvascular complications in people with type 2 diabetes mellitus. J Diabetes Complications. 2013;27:459-62.

36. Shamsheer RP, Arunachalam C. A clinical study of Meibomian gland dysfunction in patients with diabetes. Middle East Afr J Ophthalmol. 2015;22:462-6.

37. Fuerst $\mathrm{N}$, Langelier $\mathrm{N}$, Massaro-Giordano $\mathrm{M}$, et al. Tear osmolarity and dry eye symptoms in diabetics. Clin Ophthalmol (Auckland, NZ). 2014;8:507-15.

38. Berchicci L, Iuliano L, Miserocchi E, et al. Tear osmolarity in ocular graftversus-host disease. Cornea. 2014;33:1252-6.

39. Kotaniemi KM, Salomaa PM, Sihto-Kauppi K, et al. An evaluation of dry eye symptoms and signs in a cohort of children with juvenile idiopathic arthritis. Clin Ophthalmol (Auckland, NZ). 2009;3:271-5.

40. Miserocchi $\mathrm{E}$, luliano L, Berchicci L, et al. Tear film osmolarity in ocular mucous membrane pemphigoid. Cornea. 2014;33:668-72.

41. Zeng J, Chen B. Severe primary ocular surface involvement in Behçet disease. Optom Vis Sci. 2014:91:e301-4.

42. Moore QL, De Paiva CS, Pflugfelder SC. Effects of dry eye therapies on environmentally induced ocular surface disease. Am J Ophthalmol. 2015;160:135-42.e1.

43. Pinto-Fraga J, López-Miguel A, González-García MJ, et al. Topical fluorometholone protects the ocular surface of dry eye patients from desiccating stress: a randomized controlled clinical trial. Ophthalmology. 2016;123:141-53.

44. Villani E, Garoli E, Termine V, et al. Corneal confocal microscopy in dry eye treated with corticosteroids. Optom Vis Sci. 2015;92:e290-5.

45. Boynton GE, Raoof D, Niziol LM, et al. Prospective randomized trial comparing efficacy of topical loteprednol etabonate $0.5 \%$ versus cyclosporine-A $0.05 \%$ for treatment of dry eye syndrome following hematopoietic stem cell transplantation. Cornea. 2015;34:725-32.

46. Lee JH, Min K, Kim SK, et al. Inflammatory cytokine and osmolarity changes in the tears of dry eye patients treated with topical $1 \%$ methylprednisolone. Yonsei Med J. 2014;55:203-8. 